\title{
Prevalence rates of childhood trauma in medical students: a systematic review
}

\author{
Eimear King ${ }^{1}$, Claire Steenson ${ }^{1}$, Ciaran Shannon ${ }^{2}$ and Ciaran Mulholland ${ }^{1 *}$ (D)
}

\begin{abstract}
Background: It is known that medical students suffer from high rates of mental health difficulties. In recent years there has been an increasing focus on the need to improve support and treatment services for those in difficulty. In order to meet these needs it is important to clarify the relevant aetiological factors. There is robust evidence from general population studies that a history of childhood trauma (including physical and sexual abuse and emotional neglect) predisposes to the subsequent development of mental health difficulties in adult life. It has previously been speculated that students with a history of such trauma might preferentially apply to study medicine.

Methods: This systematic review seeks to examine the existing evidence base with regard to rates of childhood trauma in medical student populations. Articles were identified through a literature search of psychINFO, web of science, Embase and medline.

Results: This search generated 11 articles which were deemed to meet criteria for inclusion in this review. There is a wide range of results given for rates of childhood trauma in these studies.

Conclusions: The published research which examines rates of childhood trauma affecting medical students is limited and difficult to generalise from, or to use to draw firm conclusions. Given the possible negative outcomes of a history of childhood trauma in medical students, including that such a history may be associated with difficulties in a student progressing in their undergraduate and postgraduate examinations, well-organised prospective studies are required.
\end{abstract}

Keywords: Medical students, Mental health, Childhood trauma

\section{Background}

Most of the published literature suggests that medical students suffer higher rates of mental health difficulties than other students, and the general population. For example, when Dyrbye and colleagues carried out a systematic review of 40 American and Canadian studies published between 1980 and 2005 they found clear evidence of a higher prevalence of depression and anxiety among medical students than in the general population [1]. Whilst some recent UK studies did not find that mental health difficulties are more common in medical students-a study in Cambridge found prevalence rates of depression between 2.2 and $14.8 \%$, matching that of the general population [2], a study at University College London, found that non-medical students had higher rates of moderate to severe depression than

\footnotetext{
* Correspondence: c.c.mulholland@qub.ac.uk

${ }^{1}$ Centre for Medical Education, Department of Psychiatry, Queen's University of Belfast, 97 Lisburn Road, Belfast, Northern Ireland BT9 7BL, UK

Full list of author information is available at the end of the article
}

medical students [3] and a study at Edinburgh, found similar rates of psychological morbidity in medical and non-medical students [4]-these are at variance with the main body of literature.

One result of increasing awareness of this evidence base has been a sharper focus on the mental health needs of medical students. In the UK the General Medical Council (GMC) document Supporting Medical Students with Mental Health Conditions highlights the considerable stress suffered by medical students and the need for improved support services [5]. In order to provide such services and relevant and effective therapeutic interventions it is essential to establish the important aetiological factors which predispose to mental health problems in medical students. One such well-established aetiological factor in general population studies is a history of childhood trauma (CHT) with a large body of evidence supporting a link with the subsequent development of mental health difficulties in adult life [6]. It has 
previously been speculated that students with a history of such trauma might preferentially apply to study medicine as they may view the prospect of caring for others as therapeutic for themselves, either consciously or subconsciously [7]. There are possible negative outcomes of a history of CHT in medical students: a history of CHT may be associated with difficulties in a student progressing in their undergraduate and postgraduate examinations [8], for example. This systematic review seeks to examine the existing evidence base with regard to rates of $\mathrm{CHT}$ in medical student populations.

\section{Methods}

\section{Search strategy and selection criteria}

Articles were identified through a literature search of psychINFO, web of science, Embase and medline using the following search terms: child abuse, child sexual abuse, child neglect, physical abuse, emotional abuse, domestic violence, adult survivors of child abuse, post-traumatic stress disorder, medical student, undergraduate medical education. Searches were adapted for the different databases with Boolean operators 'AND' and 'OR'. The search was implemented separately by two reviewers using the procedure outlined by Higgins and Green [9].

Additional references were retrieved by cross-referencing of selected articled. Disagreement was resolved through discussion between the investigators.

Studies were included in this review if they met the following inclusion criteria:

(1) Original research only.

(2) Studies from any date of publication.

(3) Full text in English only.

(4) Participants to include medical students.

(5) Quantitative studies with a prevalence rate of CHT specifically for medical students.

(6) The trauma to have occurred before the age of 18 .

\section{Study selection}

A total of 735 articles were returned from the initial search. Two investigators (EK and CSt) independently reviewed all the articles with any disagreement being resolved through discussion involving all authors. The strength of agreement between the two raters was high (kappa $=0.78)$.

Of the 735 articles, 385 were removed as they were duplicates. The remaining 350 articles were screened against the inclusion and exclusion criteria. A total of 121 articles were excluded at title, a further 137 excluded at abstract and 81 excluded after the full text was read.

Reasons for exclusion after examining full texts included: papers presenting results which included trauma not specifically occurring before the age of 18; papers from which it was not possible to determine a prevalence rate related exclusively to medical students; studies which were qualitative in nature and therefore did not provide a prevalence rate.

This search generated 11 articles which were deemed to meet criteria for inclusion in the study. The references lists of these articles were examined but this do not lead to any further articles being included.

\section{Quality assessment}

A quality assessment checklist was applied to each of the studies, based on the proforma created by Kmet, Lee and Cook [10]. Criteria 5-7, applicable to studies assessing interventions, were removed. Articles were assessed for quality independently by two reviewers in an effort to improve reliability. Results of the quality assessment are presented in Table 1.

\section{Results}

Table 1 provides a summary of the 11 articles including: the geographical area where the study took place; the number of participants in the study; whether an objective validated assessment tool was used; and the rate of CHT established by the study [11-21]. The quality of each study is included in the final column. The number of study participants ranged from 106 to 6986 with a median number of 370 . Five studies were carried in the last 10 years.

A narrative review is presented as marked differences between studies made the combination of results inappropriate. The narrative analysis includes comparison of data where possible and an appraisal of study quality. For the purposes of this paper, we have organised the studies into those seeking to determine whether or not there was a history of physical abuse, sexual abuse and other forms of abuse. Studies could of course belong to more than one, or all categories.

\section{Rates of childhood physical abuse in medical students}

Ten out of the 11 studies investigated rates of childhood physical abuse (Table 2). The study which did not generate a rate of physical abuse measured 'witnessed violence by the father directed towards the mother' [11].

The rates reported ranged from 5 to $65 \%$. Two of the studies did not use a validated questionnaires but rather asked the participant to answer 'yes' or 'no' to the question 'I was physically abused as a child' [12, 13].

\section{Rates of childhood sexual abuse in medical students}

Six of the 11 studies provide rates of sexual abuse (Table 3). One study [12] asked participants to respond to the question 'as a child did you experience sexual abuse?' without defining sexual abuse. Once this study is excluded the rates of CSA reported range from $2.9 \%$ to 
Table 1 Summary of studies included in review

\begin{tabular}{|c|c|c|c|c|c|c|}
\hline $\begin{array}{l}\text { Author(s) and year of } \\
\text { publication }\end{array}$ & $\begin{array}{l}\text { Country of } \\
\text { study }\end{array}$ & $\begin{array}{l}\text { Year(s) of data } \\
\text { collection }\end{array}$ & $\begin{array}{l}\text { Number of } \\
\text { students }\end{array}$ & Type of $\mathrm{CHT}$ & $\begin{array}{l}\text { Use of validated assessment } \\
\text { tool }\end{array}$ & Quality score (/22 \\
\hline $\begin{array}{l}\text { Orhon FS et al. (2006) } \\
\text { [11] }\end{array}$ & Turkey & 2002 & 106 & Physical & No & 19 \\
\hline Xiao Q et al. (2008) [12] & China & 2004-2005 & 2073 & $\begin{array}{l}10 \text { categories including } \\
\text { emotional, physical, sexual } \\
\text { and parental discord }\end{array}$ & $\begin{array}{l}\text { Incorporated questions from } \\
\text { the Conflict Tactics Scale } \\
\text { (CTS) and the Childhood } \\
\text { Trauma Questionnaire } \\
\text { (CTQ) }\end{array}$ & 20 \\
\hline $\begin{array}{l}\text { Delahunta ET, Tulsky AA } \\
\text { (1996) [13] }\end{array}$ & USA & 1995 & 217 & Physical and sexual & No & 16 \\
\hline $\begin{array}{l}\text { Ambuel et al. (2003) } \\
\text { [18] }\end{array}$ & $\begin{array}{l}\text { Mid west } \\
\text { USA }\end{array}$ & Unclear from paper & 223 & Physical and sexual & $\begin{array}{l}\text { Incorporated questions } \\
\text { from the CTS }\end{array}$ & 20 \\
\hline $\begin{array}{l}\text { Cullinane PM, Alpert EJ, } \\
\text { Freund KM (1997) [15] }\end{array}$ & USA & 1991-1992 & 370 & Physical and sexual & $\begin{array}{l}\text { Incorporated questions } \\
\text { from the CTS }\end{array}$ & 21 \\
\hline Usta et al. (2014) [20] & Lebanon & 2009 & 545 & Physical and verbal & CTS & 20 \\
\hline $\begin{array}{l}\text { Kumaraswamy et al. } \\
\text { (2010) [19] }\end{array}$ & Malaysia & & 196 & Physical & Discipline questionnaire & 16 \\
\hline Aydin S (2006) [21] & $\begin{array}{l}\text { Kazakhstan/ } \\
\text { turkey }\end{array}$ & 2003 & 287 & Physical and sexual & No & 9 \\
\hline $\begin{array}{l}\text { Jeon HJ et al. } \\
\text { (2009) [16] }\end{array}$ & Korea & 2007 & 6986 & $\begin{array}{l}\text { Physical, emotional, Sexual, } \\
\text { general trauma }\end{array}$ & $\begin{array}{l}\text { Early trauma inventory } \\
\text { self-report - short form }\end{array}$ & 22 \\
\hline $\begin{array}{l}\text { Haj-Yahia MM, Zoysa } \\
\text { PD (2008) [17] }\end{array}$ & Sri Lanka & 2007 & 476 & Physical & CTS & 17 \\
\hline Burazeri et al. [14] & Albania & 2010 & 2797 & Witnessed violence & $\begin{array}{l}\text { Adapted from the } \\
\text { reproductive health } \\
\text { questionnaire }\end{array}$ & 18 \\
\hline
\end{tabular}

CTS conflict tactics scale, CTQ childhood trauma questionnaire

$13 \%$ across the other 5 studies. One study [13] produced two different rates of sexual abuse (6\% and 13\%) for abuse perpetrated by a family member and abuse perpetrated by a non-family member respectively. The other five studies did not make any distinctions regarding who carried out the abuse.

Table 2 Rates of childhood physical abuse

\begin{tabular}{lll}
\hline Study (Reference) & $\begin{array}{l}\text { Rate of physical } \\
\text { abuse (\%) }\end{array}$ & Quality score \\
\hline Orhon FS et al. (2006) [11] & 65 & 19 \\
Xiao Q et al. (2008) [12] & 26.7 & 20 \\
$\begin{array}{l}\text { Delahunta ET, Tulsky AA } \\
\text { (1996) [13] }\end{array}$ & 12.9 & 16 \\
Cullinane PM, Alpert EJ, & 7 & 21 \\
Freund KM (1997) [15] & & \\
Jeon HJ et al. (2009) [16] & 9.4 & 22 \\
Haj-Yahia MM, Zoysa PD & 12 & 17 \\
(2008) [17] & & 20 \\
Ambuel et al. (2003) [18] & 30 & 16 \\
Kumaraswamy et al. & 5 & 9 \\
(2010) [19] & & 20 \\
Aydin S (2006) [21] & 26.5 & \\
Usta et al. (2014) [20] & 22 & \\
\hline
\end{tabular}

\section{Rates of other trauma in childhood in medical students} Two of the studies $[12,16]$ looked at types of CHT other than physical, sexual and emotional abuse. One measured 10 different types of $\mathrm{CHT}$ [12] including experience of mental illness in the household, emotional neglect, parental discord, and experience of a family member being put in jail. This study generated a high quality score based on the large number of participants and the use of a validated questionnaire. Rates of physical neglect and physical abuse were significantly higher than emotional abuse (3.9\%). The rate of substance abuse was 15.3\% [16]. The rate of reported parental discord was $5.4 \%$. It is reasonable to assume that there was an overlap between the experiences of different forms of abuse. The second study [14] recorded rates of 'general trauma' (this included eight different types) and gave an overall rate of $13.2 \%$.

Table 3 Rates of childhood sexual abuse

\begin{tabular}{ll}
\hline Study & Rate (\%) \\
\hline Xiao Q et al. (2008) [11] & 8.3 \\
Delahunta ET, Tulsky AA (1996) [12] & 9.7 \\
Cullinane PM, Alpert EJ, Freund KM (1997) [14] & 9 \\
Jeon HJ et al. (2009) [18] & 2.9 \\
Ambuel et al. (2003) (13 & 13 \\
Aydin S (2006) [17] & 35.9 \\
\hline
\end{tabular}




\section{Discussion}

The existing research examining rates of $\mathrm{CHT}$ in medical student populations is limited both in quantity and quality. It is thus difficult to synthesis the findings or to generalise from them. Though we adopted a robust approach to quality the weakness of the evidence base meant that this did not help to clarify the situation to a significant extent. Studies of higher quality were those which: provided sufficient baseline demographic information relating to the participants; used validated assessment tools; had clearly defined thresholds for the presence of a history of CHT; and had larger, more representative samples. There are however insufficient high quality studies at this time.

A wide range of results for rates of $\mathrm{CHT}$ is reported in the studies but this is not surprising for a number of reasons. Study quality and methodologies varied considerably, for example, even something as important as what is considered to constitute CHT was not defined in ways that allowed clear comparisons between studies (and two studies did not define abuse in any way $[12,13])$. As all the studies were retrospective in design there is an obvious potential problem with recall bias. There are also issues around subjectivity though efforts have been made in some of the studies to use objective and validated assessment tools with clear definitions of abuse (including the Childhood Trauma Questionnaire, Traumatic Events Survey, and the Early Trauma Inventory Self Report). Even with the use of such tools what one individual categorises as traumatic, others may not, and indeed what an individual considers to be an abusive childhood experience may reflect cultural variation in the perception of what constitutes such an experience [22].

A further problem is that it is possible that medical students are more reluctant to disclose abusive experiences than most people, even when anonymity is guaranteed, despite the recent societal shift in attitudes towards the reporting of CHT. A particular reluctance to disclose $\mathrm{CHT}$ among the medical student population may arise because of a perception that such disclosure may in some way impede progress in their medical career. The possibility of an increasing willingness to disclose abusive experiences in childhood across wider society is demonstrated by the similar studies carried out in 1999 and 2009 by the NSPCC: the 1999 study examined the rate of 'childhood maltreatment' in the UK (in a randomly selected group of 2869 people aged between 18 and 24 years) found a rate of $16 \%$ [23] whereas the second study (2009) found that $25.3 \%$ (of a randomly selected group of 1761 people aged between 18 and 24 years) described childhood maltreatment [24]. A meta-analysis carried out in 2008 looked at the prevalence of childhood sexual abuse (CSA) around the world in student and community samples (included 65 studies from 22 countries) and showed that $7.9 \%$ of men and 19.7\% of women had suffered some form of CSA [25]. It is likely that medical students will become more willing to disclose $\mathrm{CHT}$ in line with changes in societal attitudes.

Students who receive the appropriate support at medical school are more likely to do well. An improved understanding of the likelihood of students having experienced $\mathrm{CHT}$, and of its potential consequences on well-being and educational outcomes, is essential for educators engaged in pastoral care. The demands of the medical undergraduate course are significant and students with a history of CHT may be more vulnerable to academic stress [26]. Significant rates of alcohol and drug use exist among medical students [27] and there is evidence suggesting a link between drug dependency and a history of CHT [28].

A history of CHT is not only associated with negative outcomes however. Students who have experienced their own traumas may find it easier to broach more difficult topics in the consultation. It is interesting that in a study in Massachusetts medical professionals who had experienced abuse were more confident in screening for abuse amongst those they treated [29].

\section{Conclusions}

The current research base examining rates of childhood trauma in medical student populations is very limited. Given the possible negative outcomes of a history of childhood trauma in medical students, including that such a history may be associated with difficulties in a student progressing in their undergraduate and postgraduate examinations, well-organised, large-scale prospective studies are required to clarify both the rates of such trauma, and the potential impact on future wellbeing and academic progression.

\section{Strengths and limitations}

$\mathrm{CHT}$ is a sensitive topic. Participants in research studies may not be ready to disclose traumas, or choose not to. This may be a particular problem for medical students who are often concerned about the implications of showing signs of "weakness" or to "admitting" to mental health problems.

The systematic review excluded studies in any language other than English. This may mean some relevant articles in a different language were excluded.

The studies to date have been completed over a wide timescale, during which attitudes to the reporting of CHT have changed, and have been carried out in very different societal contexts. 


\section{Funding}

No funding was received for this study.

\section{Availability of data and materials}

All papers reviewed in this study are in the public domain.

\section{Authors' contributions}

CM proposed the study idea. EK and CSt completed the initial review. CM and CSh ensured the quality of the review. All authors contributed to the final draft of the paper. All authors read and approved the final manuscript.

\section{Ethics approval and consent to participate}

Not applicable.

\section{Consent for publication}

Not applicable.

\section{Competing interests}

The authors declare that they have no competing interests.

\section{Publisher's Note}

Springer Nature remains neutral with regard to jurisdictional claims in published maps and institutional affiliations.

\section{Author details}

'Centre for Medical Education, Department of Psychiatry, Queen's University of Belfast, 97 Lisburn Road, Belfast, Northern Ireland BT9 7BL, UK. ${ }^{2}$ School of Psychology, Queen's University of Belfast, Belfast, Northern Ireland, UK.

\section{Received: 31 October 2016 Accepted: 28 August 2017}

\section{Published online: 12 September 2017}

\section{References}

1. Dyrbye LN, Thomas MR, Shanafelt TD. Systematic review of depression, anxiety, and other indicators of psychological distress among U.S. and Canadian medical students. Acad Med. 2006;81:354-73.

2. Quince TA, Wood DF, Parker R, Benson J. Prevalence and persistence of depression among undergraduate medical students: a longitudinal study at one UK medical school. BMJ Open. 2012;2:e001519. doi:10.1136/bmjopen2012-001519.

3. Honney K, Buszewicz M, Coppola W, Griffin. Comparison of levels of depression in medical and non-medical students. Clin Teach 2010; 7: 180-183.

4. Carson AJ, et al. Mental health in medical students. A case control study using the 60 item general health questionnaire. Scott Med J. 2000:45:115-6.

5. Supporting medical students with mental health conditions. GMC. http:// www.gmc-uk.org/Supporting_students_with_mental_health_conditions_ 1114.pdf_53047904.pdf. Accessed 11 Sept 2017.

6. JCarr CP, Martins CM, Stingel AM, Lemgruber VB, Juruena MF. The role of early life stress in adult psychiatric disorders: a systematic review according to childhood trauma subtypes. J Nerv Ment Dis. 2013; 201:1007-1020.

7. Johnston WD. Predisposition to emotional distress and psychiatric illness amongst doctors: the role of unconscious and experiential factors. Br J Med Psychol. 1991;64:317-29.

8. Duncan R. Childhood maltreatment and college drop-out rates: implications for child abuse researchers. J Interpers Violence. 2000;15:987-95.

9. Higgins J, Green S. (Eds.) Cochrane Handbook for Systematic Reviews of Interventions Version 5.1.0 [updated March 2011]. www.cochrane-handbook.org. Accessed 11 Sept 2017.

10. Kmet L M, Lee R C, Cook L S. Standard quality assessment criteria for evaluating primary research papers from a variety of fields. Edmonton Alberta Heritage Foundation for Medical Research (AHFMR). HTA Initiative \#13. URL http://www.ihe.ca/documents/HTA-FR14.pdf. 2004. Accessed 11 Sept 2017.

11. Orhon FS, Ulukol B, Bingoler B, Gulnar SB. Attitudes of Turkish parents, pediatric residents and medical students toward child disciplinary practices. Child Abuse Negl. 2006:30:1081-92.

12. Xiao Q, Dong MX, Yao J, Li WX, Ye DQ. Parental alcoholism, adverse childhood experiences, and later risk of personal alcohol abuse among Chinese medical students. Biomed Environ Sci. 2008;21:411-9.

13. DeLahunta EA, Tulsky AA. Personal exposure of faculty and medical students to family violence. J Am Med Assoc. 1996;275:1903-6.
14. Burazeri G, Qirjako G, Roshi E, Brand H. Determinants of witnessed parental physical violence among university students in transitional Albania. J Public Health (Oxf). 2010;33:22-30.

15. Cullinane PM, Alpert EJ, Freund KM. First-year medical students' knowledge of, attitudes toward, and personal histories of family violence. Acad Med. 1997;72:48-50.

16. Jeon HJ, Roh MS, Kim KH, Lee JR, Lee D, Yoon SC, Hahm BJ. Early trauma and lifetime suicidal behavior in a nationwide sample of Korean medical students. J Affect Disord. 2009:119:210-4.

17. Haj-Yahia MM, de Zoysa P. Rates and psychological effects of exposure to family violence among Sri Lankan university students. Child Abuse Negl. 2008;32:994-1002.

18. Ambuel B, Butler D, Hamberger LK, Lawrence S, Guse C. Female and male medical students' exposure to violence: impact on well-being and perceived capacity to help battered women. J Comp Fam Stud. 2003:34:113-35.

19. Kumaraswamy N, Othman A. Corporal punishment study: a case in Malaysia. Psychology. 2011:2:24-8.

20. Usta J, Hlais S, Farhat HA, Romani M, Bzeih H, Abdo L. Lebanese medical students' exposure to domestic violence: does it affect helping survivors? Fam Med. 2014:46:112-9.

21. Aydin S. Domestic violence experiences among medical students in two universities. Saudi Med J. 2006:27:125-7.

22. Ecker N. Culture and sexual scripts out of Africa: a north American trainer's view of taboos, tradition, trouble and truth. SIECUS Rep. 1994;22:16-22.

23. Cawson P, May-Chahal C. Measuring child maltreatment in the United Kingdom (UK): a study of the prevalence of child abuse and neglect. Child Abuse Negl. 2005;29:969-84.

24. Child abuse and neglect in the UK today, NSPCC, 2011. Available from http://www.nspcc.org.uk/Inform/research/findings/child_abuse_neglect_ research_wda84173.html. Accessed 25 Jan 2014

25. Pereda N, Guilera G, Forns M, Gomez - Benito J. The prevalence of child sexual abuse I community and student samples: a meta-analysis. Clin Psychol Rev 2009: 29: 328 - 228.

26. Lee J, Graham AV. Students' perception of medical school stress and their evaluation of a wellness elective. Med Educ. 2001:35:617-8.

27. Webb E, Ashton CH, Kelly P, Kamali F. An update on British medical students' lifestyles. Med Educ. 1998:32:325-31.

28. Medrano MA, Zule WA, Hatch J, Desmond DP. Prevalence of childhood trauma in a community sample of substance-abusing women. Am J Drug Alcohol. 1999;25:449-62.

29. Candib LM, Savageau JA, Weinreb LF, Reed GW. Inquiring into our past: when the doctor is a survivor of abuse. Fam Med. 2012:44:416-24.

\section{Submit your next manuscript to BioMed Central and we will help you at every step:}

- We accept pre-submission inquiries

- Our selector tool helps you to find the most relevant journal

- We provide round the clock customer support

- Convenient online submission

- Thorough peer review

- Inclusion in PubMed and all major indexing services

- Maximum visibility for your research

Submit your manuscript at www.biomedcentral.com/submit
Biomed Central 